\title{
ИСТОРИЯ
}

\section{МЕЖДУНАРОДНЫХ ОТНОШЕНИЙ}

\author{
Буранок С. O.
}

\section{ОБЩЕСТВЕННО-ПОЛИТИЧЕСКИЕ СИЛЫ США И УГРОЗА ВОЙНЫ 1938-1939 ГГ.}

\begin{abstract}
Аннотация. В статье рассмотрена реакция общества США на кризисные моменты международных отношений 1938-1939 г2. Проанализированы оченки прессой и лидерами США агрессии Германии в Европе. В американском обществе 1920-х - 1930-х г2. по такой проблеме, как осознание угрозы войны, боролись две тенденции, выраженные "изоляционистами», с одной стороны, и «интернационалистами», с другой. В данной ситуации особое влияние получала фигура президента США Франклина Рузвельта, который с большим вниманием относился как к европейским, так и дальневосточным делам. Первый крупный европейский кризис 1938 г. связан с оккупацией Австрии, вызвавшей широкий резонанс в обществе США. Формирование оценки фашистской угрозы происходило как под влиянием СМИ, так и мнений ведущих политиков, среди которых выделялась позиция сотрудников госдепартамента. Государственный секретарь Корделл Халл перед мартовским кризисом 1938 г. писал, что "Германия становится доминирующей силой в континентальной Европе» и, учитывая этот фактор (объяснял госсекретарь послу Германии Дикхоффру), надлежит определить дальнейщий путь - или сохранение текущего порядка в Европе, или милитаризация и конфлликты.
\end{abstract}

Ключевые слова: международные отношения, политика, США, Германия, конфлликты, общество, угроза, война, интересы, ценности.

$\Pi$ римерно о такой же проблемме ${ }^{1}$ рассуждал в преддверии европейского кризиса помощник государственного секретаря США Дж. Мессерсмит, который указывал, что захват Австрии и Чехословакии приведёт к установлению господства Германии в Юго-Восточной Европе; захвату Украины; изоляции России; ослаблению Франции путем расторжения ее союза с Россией; и к постепенному расчленению Британской империи ${ }^{2}$. Из этих заявлений видно, что правительство Соединенных Штатов Америки было хорошо информировано об агрессивных планах Германии и находилось перед началом мартовского кризиса под впечатлением от «карантинной речи» президента Рузвельта, произ-

\footnotetext{
${ }^{1}$ Статья «Общественно-политические силы США и угроза войны 1938-1939 гг.»

подготовлена в рамках ФЦП «Научные и научно-педагогические кадры инновационной России», соглашение № 14. B37.21.0491.

${ }^{2}$ Foreign Relations of the United States. 1937, vol. I. Washington, 1954. P. $140-145$
}

несённой 5 октября 1937 г. в Чикаго, где требовалось введение "карантина» для агрессора ${ }^{3}$.

Однако, убеждённость в необходимости противостояния агрессорам (пусть даже только экономическими методами, к котором особо апеллировал Халл ${ }^{4}$ ) сочеталась с надеждами, что Гитлер не будет развязывать войну против «демократий Запада», пока он не ликвидирует угрозу на Востоке, пока не уничтожит СССР. О наличии данных идей пишет в воспоминаниях заместитель государственного секретаря США С. Уэллес ${ }^{5}$.

Поэтому, когда произошла оккупация Австрии войсками Германии, оценки периодической печати США этого события разделились. Часть изданий выступила с открытой критикой, называя действия Гитлера «перекраиванием карты Европы» и захватом ресурсов и промышленности Австрии под предло-

\footnotetext{
${ }^{3}$ Марушкин Б. И. Американская политика «невмешательства» и японская агрессия в Китае 1937-1939. М.,1957. С. 39.

${ }^{4}$ Peace and War: United States Foreign Policy 1931-1941. Washington, 1983. P. 401-402.

${ }^{5}$ Welles S.. Seven Decisions that Shaped History. N.Y., 1950. P. 25.
} 


\section{История международных отношений History of international relations}

гом заботы о соотечественниках ${ }^{1}$. На первой полосе «Milwaukee Journal» была размещена карикатура, на которой согнувшийся Гитлер на коленях, с вилкой ползёт к пирогу, а над ним возвышается грозного вида дама со скалкой. Здесь хорошо просматривается явный намёк американских журналистов на слабость нацистского режима, на то, что Гитлер эту слабость прекрасно знает, а также на необходимость силового решения кризиса (образ скалки на карикатуре). В негативном свете об установлении нового нацистского порядка в Центральной Европе сообщают и другие периодические издания США². А в «Pittsburgh PostGazette» прямо написано: «Гитлер рвётся к Вене, и Европа чувствует приближение войны из-за нацистского переворота» ${ }^{3}$.

Другая часть газет под влиянием «New York Times' расставила совсем иные акценты по поводу австрийских событий. «Не стоит ожидать попытки, чтобы вмешаться в рамках Лиги против гитлеровского путча в Австрии»,- заявила авторитетная нью-йоркская газета ${ }^{4}$. Кроме того, по мнению редакторов «New York Times», судьба Австрии была решена ещё 18 февраля и, следовательно, не стоит нарушать мир и дестабилизировать ситуацию в Европе, если основные участники уже смирились с оккупацией ${ }^{5}$.

Позиция Рузвельта в этом вопросе хорошо прослеживается по его частному письму Нельсону Уоррену, где президент относительно беспокойств по поводу «австрийской проблемы» прямо написал, что одобряет действия госдепартамента и что последний был хорошо информирован ${ }^{6}$.

Видно, что оккупация Австрии разделила американское общество, но по совершенно иным группам, нежели во Франции (где сразу выделились "сопротивленцы» и "умиротворители»). В США и СМИ, и политики размежевались на критиков действий Гитлера, и на апологетов аншлюса. Однако, критики не призывали к силовым решениям, не требовали сопротивления агрессорам, а выступали лишь с осуждением. Поэтому, ко времени Судетского кризиса, общественность Соединённых Штатов стала рассматривать политику Германии не как угрозу войны, а как

\footnotetext{
${ }^{1}$ Milwaukee Journal. 12.03.1938. P. 1, 2.

${ }^{2}$ Herald-Journal. 12.03.1938. P. 1; Los Angeles Times. 12.03.1938. P. 1; Washington Times-Herald. 12.03.1938. P. 1.

${ }^{3}$ Pittsburgh Post-Gazette. 12.03.1938. P. 1.

${ }^{4}$ New York Times. 13.03.1938. P. 31.

${ }^{5}$ New York Times. 13.03.1938. P. 2.

${ }^{6}$ The Franklin Delano Roosevelt Library. German Diplomatic Files. Box 31.
}

попытки объединения с соотечественниками, законные и объективные, а действия Франции (и особенно малых стран Европы) воспринимались американским обществом как лишённое мудрости сопротивление и провоцирование войны в Европе.

Американская пресса с большим вниманием отнеслась к сентябрьскому кризису 1938 г. Особенно к позициям заинтересованных сторон. Так, «Milwaukee Journal» от 23 сентября 1938 г. писал о миротворческой позиции Великобритании, сопротивленческих настроениях во Франции и агрессивных намерениях Польши и СССР, которые стремятся под предлогом чехословатского кризиса развязать войну”. «New York Times' занимает похожую позицию, сконцентрировавшись не на шантаже Гитлера, а на польском ультиматуме и претензиях Польши к Чехословакии ${ }^{8}$, а именно: «... решить проблему на территориях, населенных поляками в том же порядке, как и на территориях с немецкого населением»". "Pittsburgh Press' от 24 сентября писала, что СССР угрожает Польше разорвать пакт о ненападении ${ }^{10}$.

Видно, что пресса США создавала в самые напряжённые дни кризиса следующую картину: Германия выступает с вполне понятными и обоснованными требованиями о защите прав немцев в Чехословакии, но этим решают воспользоваться Польша и Советский Союз, провоцируя, каждый в своих интересах, полномасштабную войну в Европе. Причём, газеты США часто писали в сентябре 1938 г., что Сталин использует политику Гитлера для попытки сокрушения «мирового империализма». При таких акцентах полностью изменялись и искажались представления граждан США об истиной угрозе войны, о подлинном нарушении международных договоров Германией, о целях внешней политики фашизма.

Перед самым заключением Мюнхенского договора СМИ США, Великобритании, Франции, Канады настойчиво обращают внимание на формируемую ими же «проблему Украины». Так, «Milwaukee Journal» писал, что «Украина - это не часть России, ее население никогда не говорило по-русски, зато Украина даёт СССР $80 \%$ угля, 60\% железной руды, 65\% зерна, 95\% марганца» ${ }^{11}$. У американских читателей создавалось впечатление, что Украина - это угнетаемая колония Советского Союза и её «освобождение» Польшей

\footnotetext{
${ }^{7}$ Milwaukee Journal. 23.09.1938. P. 1, 2.

${ }^{8}$ New York Times. 24.09.1938. P. 3.

${ }^{9}$ New York Times. 23.09.1938. P. 1.

${ }^{10}$ Pittsburgh Press. 23.09.1938. P. 3.

${ }^{11}$ Milwaukee Journal. 23.09.1938. P. 2.
} 


\section{Международные отношения International Relations}

и Германией будет логичным и правильным шагом такие мысли высказывались в американских периодических изданиях на протяжении всего сентября 1938 г.

В этом свете очень важным является пресс-релиз госдепартамента США от 26 сентября, подписанный президентом Рузвельтом. В нём Рузвельт обращается к президенту Чехословакии и канцлеру Германии с призывом к миру и приводит многочисленные аргументы против войны: «Экономика стран может быть разрушена. Социальная структура каждого государства может быть полностью разрушена» ${ }^{1}$. Это явный намёк на возможные выгоды СССР в результате европейской войны, о чём так настойчиво писала американская пресса.

Ещё один аргумент Рузвельта: «Очень важно, что все народы вспомнили, что каждое цивилизованное государство в мире добровольно приняло на себя торжественные обязательства пакта КеллогаБриана 1928 года - решать споры только мирными методами»². Это уже не намёк, а прямой призыв к Чехословакии прекратить сопротивление и принять ультиматум Германии, а Англии и Франции - не вмешиваться (как раз в СМИ США в период 24-26 сентября появились опасения по поводу мобилизации «западных демократий»³). Завершался пресс-релиз словами о том, что «во время нынешнего кризиса народ Соединенных Штатов и правительство искренне надеялись, что переговоры по корректировке тех противоречий, которые сейчас возникли в Европе, могут достичь успешного завершения» ${ }^{4}$.

Такая позиция президента, госдепартамента и общественности США облегчила налаживание переговорного процесса и способствовала заключению мюнхенских соглашений, которые были встречены в США почти с полным одобрением. Газеты разместили на передовицах крупные заголовки: «Чешский кризис закончился подписанием четырёхстороннего соглашения» Война в Европе предотвращена» ${ }^{6}$; “Большая четвёрка приняла мирный план»7. И неизменно указывалось,

\footnotetext{
${ }^{1}$ Peace and War: United States Foreign Policy 1931-1941. Washington, 1983. P. 425.

2 Peace and War: United States Foreign Policy 1931-1941. Washington, 1983. P. 425.

${ }^{3}$ Washington Times-Herald. 24.09.1938. P. 1; Wall Street Journal. 25.09.1938. P. 1; Chicago Daily Tribune. 24.09.1938. P. 1, 2.

${ }^{4}$ Peace and War: United States Foreign Policy 1931-1941. Washington, 1983. P. 426.

${ }^{5}$ Herald-Journal. 30.09.1938. P. 1.

${ }^{6}$ New York Times. 30.09.1938. P. 1.

${ }^{7}$ Lewiston Daily Sun. 30.09.1938. P. 1.
}

что только Советский Союз выступил против данных соглашений, что воспринималось общественностью США как «СССР против мира».

Однако, как отмечал К.А. Уманский в письме М.М. Литвинову, «в США в целом антифашистские настроения сильны. Послемюнхенское похмелье наступило скорее, чем в Европе, и имеет более всеобщий характер. Это сочетается, однако, с новым усилением изоляционизма, с резким падением доверия к Англии как к возможному партнёру в отпоре японцам ${ }^{8}$. Видно, что советский дипломат очень точно проанализировал и охарактеризовал положение в американском обществе по поводу угрозы войны на ноябрь 1938 г.

Как раз в 1938 г. в Конгрессе (и в обществе США в целом) проходили ожесточённые дебаты по поводу программы усиления армии и флота, которую предложил президент Рузвельт ${ }^{9}$. Она носила ярко выраженный антияпонский характер, и с этого времени главным источником стабильности и безопасности мира в США воспринималась Япония ${ }^{10}$. Это отмечает в своём письме и К. А. Уманский: республиканцы в Конгрессе могут выступать с антияпонскими речами, но поддерживают мюнхенские соглашения, а ведущие послы США в европейских странах их полностью одобряют ${ }^{11}$. Следовательно, можно заключить, что в конце 1938 г. в вопросе об угрозе войны американское общество различало угрозу со стороны Японии, как наиболее опасную и реальную, и угрозу со стороны Германии и Италии, но сохранялась вера, что последнюю удастся скорректировать в восточном направлении.

Переход стран-аргрессоров от политики шантажа войной к полномасштабному общеевропейскому конфликту вызывает в США настоящий всплеск антинацистских настроений. «New York Times' выходит 1 сентября 1939 г. с заголовком «Мобилизация польских граждан для противостояния вторжению Германии»12. «Milwaukee Journal» - главное издание штата Висконсин с тиражом в почти 300000 экземпляров - была более категорична в тот день: «Польские города бомбят. Нацисты начали войну без объявления. Призыв помощи послан Англии и Франции; Италия держится в стороне» ${ }^{13}$.

\footnotetext{
${ }^{8}$ Год кризиса: 1938-1939. Т. 1. М., 1990. С. 101.

9 Об этом так же пишет К.А. Уманский, см.: Год кризиса: 1938-1939. T. 1. M., 1990. C. 100.

${ }^{10}$ См.: Буранок С. О. Пёрл-Харбор в оценке военно-политических деятелей США 1941-1945 гг. Самара, 2009. С. 101-104.

${ }^{11}$ Год кризиса: 1938-1939. Т. 1. М., 1990. С. 100-101.

${ }^{12}$ New York Times. 1.09.1939. P. 1.

${ }^{13}$ Milwaukee Journal. 1.09.1939. P. 1.
} 


\section{История международных отношений History of international relations}

Но большинство периодических изданий США (как республиканской, так и демократической направленности) сосредоточило 1 сентября основное внимание не на боевых действия в Польше, а на реакции администрации Белого Дома и самого президента. «Christian Science Monitor» на первой полосе опубликовал «призыв Рузвельта к нациям прекратить уничтожение гражданского населения» ${ }^{1}$. Этот же призыв, снабжённый комментариями, опубликовали ведущие периодические издания США⿱2 . А в «Milwaukee Journal» воззвание главы Белого Дома предстало в более развёрнутом виде: «Президент Рузвельт объявил, что верит: Соединённые Штаты не будут втянуты в войну, призвав Британию, Францию, Германию, Италию и Польшу не атаковать гражданское население»³. Видно, что руководство США к этому времени осознало губительные последствия политики умиротворения, однако, в год перед выборами Рузвельт не спешил сообщать населению о неизбежности скорого вовлечения США в общеевропейский конфликт. Учитывая влияние изоляционистскихтенденций, исходивших, прежде всего, от республиканской партии и Конгресса, президент делает акцент на «варварстве войны» и строгом соблюдении, даже охране, существующего нейтрального положения США.

Именно в этом ключе и воспринял призыв Рузвельта один из ведущих редакторов агентства «Юнайтед пресс» Говард Монти. В статье «Рузвельт дал клятву избежать войну» журналист прокомментировал реакцию высшей власти и общественности США на начало войны. «Сегодня президент Рузвельт пообещал приложить все усилия для удержания США вдали от войны. Также он объявил об отставке посла США в Германии ХьюУилсона. На прессконференции президент сказал, что искренне надеется, что эта страна останется в мире» ${ }^{4}$. Хорошо видно, что именно выделили как главное из речи президента американские журналисты: двойное обещание остаться вне сферы конфликта.

Однако, журналисты, по словам Г. Монти, оказались такой «клятвой» не вполне удовлетворены, и первый же вопрос на пресс-конференции был «о шансе этой страны остаться в стороне от войны». Рузвельт сказал: «Я не только надеюсь, но и верю: мы останемся в стороне, и каждое действие администрации будет направлено на это» ${ }^{5}$. Таким образом,

\footnotetext{
${ }^{1}$ Christian Science Monitor. 1.09.1939. P. 1.

${ }^{2}$ Washington Post. 1.09.1939. P. 1; New York Herald Tribune. 1.09.1939. P. 1; Chicago Daily Tribune. 1.09.1939. P. 1.

${ }^{3}$ Milwaukee Journal. 1.09.1939. P. 1.

${ }^{4}$ Pittsburgh Press. 1.09.1939. P. 1.

${ }^{5}$ Pittsburgh Press. 1.09.1939. P. 10.
}

Рузвельт за короткую встречу с представителями СМИ три раза пообещал сохранить нейтралитет. Это чётко демонстрирует весь комплекс вызванных войной сомнений и опасений в американском обществе, поэтому президент 1 сентября 1939 г. занял почти изоляционистскую позицию, заявив, что «созыв конгресса для выработки закона о нейтралитете - дело не первостепенной важности и что сегодня не следует ожидать обсуждения закона о нейтралитете» ${ }^{6}$.

Именно на этом, на непоколебимости принципов закона о нейтралитете настаивали сенаторы-изоляционисты во главе с У. Бором . Другим важным шагом по отстаиванию изоляционистской позиции стало обращение Герберта Гувера 3 сентября 1939 г., озаглавленное "Америка должна остаться вне войны». В обращении по радио бывший президент США выразил взгляды, господствовавшие не только в республиканской элите, но и среди простых граждан: «Америка должна держаться подальше от европейской войны, ради сохранения цивилизации, основанной на демократии и свободе. Завоевание Польши может продлиться ещё несколько месяцев, но, кажется, нет такой позиции, из которой решающую атаку, быстро завершающую войну, могут нанести Британия и Франция, с одной стороны, и Германия и Италия, с другой. Это будет война на медленное истощение» ${ }^{8}$.

Получается, по Гуверу, у США в новой войне особая миссия, не простое получение экономической выгоды от затяжного конфликта, но и сохранение важнейших национальных основ, к которым Гувер прибегает и как к аргументам против войны. Гувер сказал, что «нынешняя ситуация - не результат деятельности народа Германии, а только группы лиц, держащей народ в подчинении. Вся нацистская система отвратительна американскому народу. Большинство американских симпатий на стороне демократии. Однако, наши симпатии не могут решить европейские проблемы. Америка должна держаться подальше от этой войны. Президент и Конгресс должны поддерживать любое решение, удерживающее нас от войны. Мы сможем удержаться, если нация будет непоколебима в этом. Мы будем более полезны Европе и человечеству, если сохраним силу и жизнестойкость Соединённым Штатам ${ }^{9}$. Бывший президент здесь очень точно охарактеризовал настрой американских общественно-политических сил, которые видели угрозу войны

\footnotetext{
${ }^{6}$ Pittsburgh Press. 1.09.1939. P. 10.

${ }^{7}$ Печатнов В. О., Маныкин А.С. История внешней политики США. M., 2012. C. 237.

${ }^{8}$ Reading Eagle. 3. 09. 1939. P. 1.

${ }^{9}$ Reading Eagle. 3. 09. 1939. P. 1.
} 


\section{Международные отношения International Relations}

не в самой Германии или Италии, а в их руководстве, с которым до сентября 1939 г. сохранялись надежды либо договориться, либо переориентировать аргессию со стран Запада на Восток - против СССР. Но захват Чехословакии, жёсткая риторика Гитлера, Муссолини и, наконец, нападение на Польшу убедили «американскую аудиторию, что вести конструктивный диалог с гитлеровской Германией невозможно» ${ }^{1}$.

Однако, в новых, уже военных условиях консолидации общественно-политических сил США по вопросам войны, мира и угрозы агрессии не происхо- дит. Наоборот, как республиканцы, так и демократы начали использовать события Второй мировой войны для своих внутри- и внешнеполитических целей, связанных, прежде всего, с предвыборной гонкой. И публикации в прессе США периода весны 1938 г.начала осени 1939 г. показывают, что позиция Гувера и изоляционистов вызывала большую общественную поддержку и Рузвельту даже в первые дни войны приходилось чрезвычайно осторожно добиваться изменений в настроениях общественности в целом, и в законодательстве о нейтралитете, в частности.

\section{Библиография}

1. Foreign Relations of the United States. 1937, vol. I. Washington, 1954. P. 140-145

2. Марушкин Б. И. Американская политика «невмешательства» и японская агрессия в Китае 1937-1939. M.,1957. С. 39.

3. Peace and War: United States Foreign Policy 1931-1941. Washington, 1983. P. 401-402.

4. Welles S.. Seven Decisions that Shaped History. N.Y., 1950. P. 25.

5. Milwaukee Journal. 12.03.1938. P. 1, 2.

6. Herald-Journal. 12.03.1938. P. 1;

7. Los Angeles Times. 12.03.1938. P. 1;

8. Washington Times-Herald. 12.03.1938. P. 1.

9. Pittsburgh Post-Gazette. 12.03.1938. P. 1.

10. New York Times. 13.03.1938.

11. The Franklin Delano Roosevelt Library. German Diplomatic Files. Box 31.

12. Milwaukee Journal. 23.09.1938. P. 1, 2.

13. Pittsburgh Press. 23.09.1938. P. 3.

14. Peace and War: United States Foreign Policy 1931-1941. Washington, 1983.

15. Herald-Journal. 30.09.1938. P. 1.

16. New York Times. 30.09.1938. P. 1.

17. Lewiston Daily Sun. 30.09.1938. P. 1.

18. Год кризиса: 1938-1939. Т. 1. М., 1990. С. 101.

19. Уманский, К.А. см.: Год кризиса: 1938-1939. Т. 1. М., 1990. С. 100.

20. Буранок С. О. Пёрл-Харбор в оценке военно-политических деятелей США 1941-1945 гг. Самара, 2009. С. 101-104.

21. Christian Science Monitor. 1.09.1939. P. 1.

22. Washington Post. 1.09.1939. P. 1;

23. New York Herald Tribune. 1.09.1939. Р. 1;

24. Печатнов В. О., Маныкин А. С. История внешней политики США. М., 2012. С. 325.

25. Манойло А.В. Ценностные основы управления межцивилизационными конфликтами: российская модель // NB: Международные отношения.-2012.- 1._C. 32-43. DOI: 10.7256/2306-4226.2012.1.279. URL: http:// www.e-notabene.ru/wi/article_279.html

26. Овсянникова О.А., Кузнецова А.А. исторические и современные социально-политические основы российского патриотизма // NB: Международные отношения.- 2013.- 3.- C. 87-114. URL: http://www.enotabene.ru/wi/article_9083.html

27. Манойло А.В. «Сирийский вопрос» Башара Асада // NB: Международные отношения.- 2013.- 2.- C. 48-67. URL: http://www.e-notabene.ru/wi/article_8798.html

28. Борисенков А. А. О мировой политике как особой разновидности политического влияния // NB: Проблемы общества и политики.-2013.- 2.-C. 1-22. URL: http://www.e-notabene.ru/pr/article_61.html

${ }^{1}$ Печатнов В.О., Маныкин А.С. История внешней политики США. М., 2012. C. 325. 


\section{References (transliterated)}

1. Foreign Relations of the United States. 1937, vol. I. Washington, 1954. R. 140-145

2. Marushkin B. I. Amerikanskaya politika «nevmeshatel'stva» i yaponskaya agressiya v Kitae 1937-1939. M.,1957. S. 39.

3. Peace and War: United States Foreign Policy 1931-1941. Washington, 1983. R. 401-402.

4. Welles S.. Seven Decisions that Shaped History. N.Y., 1950. P. 25.

5. Milwaukee Journal. 12.03.1938. R. 1, 2.

6. Herald-Journal. 12.03.1938. R. 1;

7. Los Angeles Times. 12.03.1938. R. 1;

8. Washington Times-Herald. 12.03.1938. R. 1.

9. Pittsburgh Post-Gazette. 12.03.1938. R. 1.

10. New York Times. 13.03.1938.

11. The Franklin Delano Roosevelt Library. German Diplomatic Files. Box 31.

12. Milwaukee Journal. 23.09.1938. R. 1, 2.

13. Pittsburgh Press. 23.09.1938. R. 3.

14. Peace and War: United States Foreign Policy 1931-1941. Washington, 1983.

15. Herald-Journal. 30.09.1938. R. 1.

16. New York Times. 30.09.1938. R. 1.

17. Lewiston Daily Sun. 30.09.1938. R. 1.

18. God krizisa: 1938-1939. T. 1. M., 1990. S. 101.

19. Umanskii, K.A. sm.: God krizisa: 1938-1939. T. 1. M., 1990. S. 100.

20. Buranok S. O. Perl-Kharbor v otsenke voenno-politicheskikh deyatelei SShA 1941-1945 gg. Samara, 2009. S. 101-104.

21. Christian Science Monitor. 1.09.1939. R. 1.

22. Washington Post. 1.09.1939. R. 1;

23. New York Herald Tribune. 1.09.1939. R. 1;

24. Pechatnov V. O., Manykin A. S. Istoriya vneshnei politiki SShA. M., 2012. S. 325.

25. Manoilo A.V. Tsennostnye osnovy upravleniya mezhtsivilizatsionnymi konfliktami: rossiiskaya model» // NB: Mezhdunarodnye otnosheniya.- 2012.- 1.- C. 32-43. DOI: 10.7256/2306-4226.2012.1.279. URL: http:// www.e-notabene.ru/wi/article_279.html

26. Ovsyannikova O.A., Kuznetsova A. A. istoricheskie i sovremennye sotsial'no-politicheskie osnovy rossiiskogo patriotizma // NB: Mezhdunarodnye otnosheniya.- 2013.- 3.- C. 87-114. URL: http://www.e-notabene.ru/ wi/article_9083.html

27. Manoilo A. V. «Siriiskii vopros' Bashara Asada // NB: Mezhdunarodnye otnosheniya.- 2013.-2._ C. 48-67. URL: http://www.e-notabene.ru/wi/article_8798.html

28. Borisenkov A. A. O mirovoi politike kak osoboi raznovidnosti politicheskogo vliyaniya // NB: Problemy obshchestva i politiki.-2013.- 2.-C. 1-22. URL: http://www.e-notabene.ru/pr/article_61.html 